\title{
Reengenharia da Interface de um Jogo Educativo Usando Princípios de Design de Interação e Usabilidade
}

\author{
Elison Nascimento \\ FASI \\ UFPA \\ Cametá-PA, Brasil \\ elison_cn@hotmail.com
}

\author{
Carlos Portela \\ FASI \\ UFPA \\ Cametá-PA, Brasil \\ csp@ufpa.br
}

\author{
Antônio Moreira \\ FASI \\ UFPA \\ Cametá-PA, Brasil \\ antonio.vicente290794 \\ @gmail.com
}

\author{
Allan Costa \\ FASI \\ UFPA \\ Cametá-PA, Brasil \\ allancosta@ufpa.br
}

\begin{abstract}
RESUMO
Jogos educativos são cada vez mais utilizados em salas de aula. Entretanto, o desenvolvimento destes jogos não segue etapas básicas requeridas pela indústria de games, como os princípios de Interação Humano-Computador (IHC). Este pôster apresenta um estudo de caso da aplicação de princípios de design de interação e usabilidade na reengenharia da interface do jogo ProComunique. Inicialmente, foi definido e aplicado um projeto de interface para reengenharia do jogo-alvo da pesquisa. Posteriormente, um grupo de seis especialistas avaliou a interface desse jogo de acordo com a norma ISO/IEC 9126. Espera-se que esta pesquisa possa incentivar a utilização de princípios de IHC no desenvolvimento de jogos educativos, a fim de que estes obtenham êxito no apoio ao processo de ensino-aprendizagem.
\end{abstract}

\section{PALAVRAS-CHAVE}

Reengenharia, Interface Gráfica, Jogo Educativo, Interação Humano-Computador

\section{Contexto e Problemática}

Os jogos digitais são utilizados nas mais diversas áreas do conhecimento, como por exemplo, Português, Matemática, História e Geografia. Para a construção de jogos voltados à educação, faz-se necessária a utilização de diversas técnicas de desenvolvimento. Dentre essas técnicas, é importante ressaltar a aplicação de princípios da Interação Humano-Computador (IHC), para tornar os jogos ferramentas que auxiliem no aprendizado e não dificulte a compreensão dos usuários finais.

No entanto, os princípios de IHC acabam muitas vezes sendo negligenciadas, como foi o caso do ProComunique, um jogo educativo que permite ao usuário configurar os conteúdos que deseja utilizar como objeto de aprendizagem, uma vez que, o

Permission to reproduce or distribute, in whole or in part, material extracted from this work, verbatim, adapted or remixed, as well as the creation or production from the content of such work, is granted without fee for non-commercial use, provided that the original work is properly credited.

IHC 2019 - TRILHA PÔSTERES E DEMONSTRAÇÕES, Outubro 21-25, 2019,

Vitória, Brasil. In Anais Estendidos do XVIII Simpósio Brasileiro sobre Fatores Humanos em Sistemas Computacionais. Porto Alegre: SBC.

(C) 2019 by the author(s), in accordance with the terms of the Creative Commons Attribution-NonCommercial 4.0 International Public License (CC BY-NC 4.0). usuário pode cadastrar e gerenciar as categorias (numerais, por exemplo) que deseja trabalhar.

Mediante o contexto exposto, este pôster apresenta um relato da reengenharia do jogo educativo ProComunique a fim de aplicar princípios de IHC na criação da sua interface. A fim de validar essa nova interface, um grupo de seis especialistas realizou a avaliação do sistema, conforme os princípios de Usabilidade presentes na norma ISO/IEC 9126.

\section{Solução Proposta: Reengenharia da Interface}

2.1.1 Tela Inicial. Possuía uma mensagem de boas-vindas em inglês, sendo que a linguagem padrão é português, e uma animação de um avião, que chamava a atenção do usuário. A leitura do texto de boas-vindas, bem como dos ícones no rodapé, ficou prejudicada pela imagem de fundo, conforme a Figura 1-A.

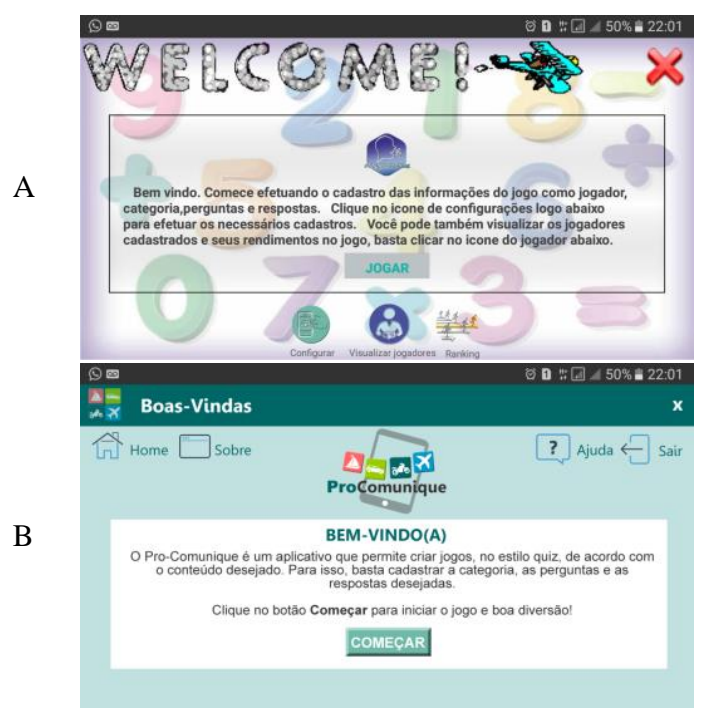

Figura 1: Tela Inicial do Aplicativo

Para aplicar o princípio de Apreensibilidade, foi proposta uma nova tela de boas-vindas, conforme mostra a Figura 1-B. Adicionalmente, o uso de ícones familiares permite que o usuário associe o que ocorrerá caso clique em determinada opção. Um exemplo é o uso do ícone de casa como analogia à página inicial. 
2.1.2 Configurar Jogo. Ao clicar em Jogar, o usuário era redirecionado para tela de configuração. $\mathrm{O}$ fundo escolhido para essa tela também prejudicou sobremaneira o menu apresentado, pois o excesso de cores acabou poluindo a aplicação e comprometendo a legibilidade das opções, conforme Figura 2-A.

A

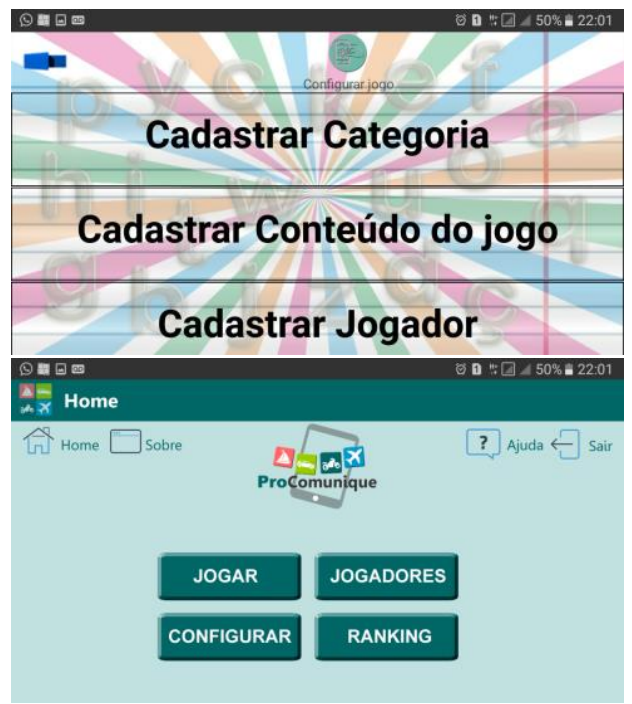

Figura 2: Tela Configurar Jogo

Foi proposta a reformulação do Estilo de Interação de Menus, que torna a aplicação mais simples de ser compreendida, pois os itens são autoexplicativos. Assim, na Figura 2-B, utilizou-se botões a fim de facilitar a navegação nas funções do aplicativo.

2.1.3 Tela de Perguntas. Na tela de interação com os usuários/alunos, o aplicativo exibia no fundo nuvens no topo e lápis no rodapé, com cores bem vivas. Essas imagens e cores acabavam competindo tanto com a pergunta realizada quanto com as opções de respostas, conforme mostra a Figura 3-A.

A

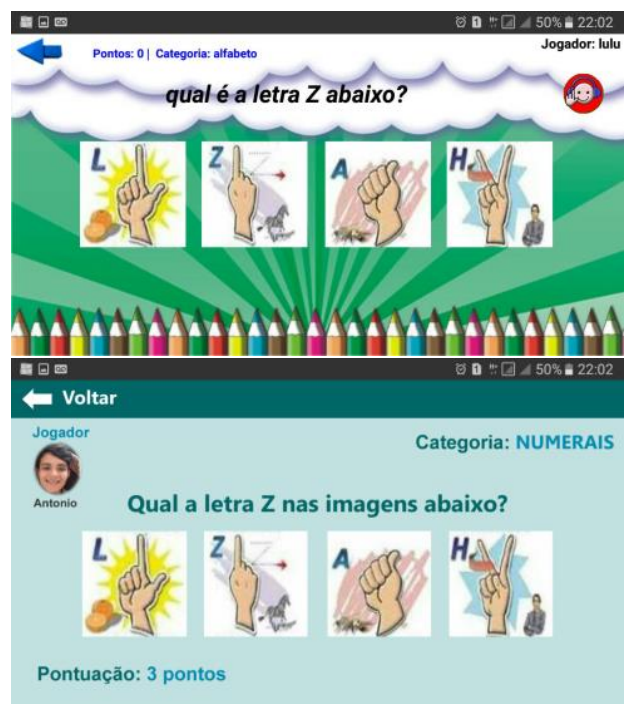

Figura 3: Tela de Perguntas
Para aplicar o princípio de Operacionalidade, padronizou-se a cor de fundo, retirando-se a imagem (ver Figura 3-A) que poderia atrapalhar à visualização das opções de respostas. Além disso, organizaram-se as informações na tela, conforme a Figura 3-B: no canto superior esquerdo, tem-se nome e foto do jogador; a categoria a qual a pergunta pertence no canto superior direito; a pontuação atual do jogador na parte de baixo da tela; no centro, a pergunta (desafio) e suas respectivas opções de resposta.

A aplicação dos demais princípios de Design de Interação e Usabilidade encontra-se disponível no projeto de interface em https://bit.ly/2YNt9pj, sob licença Creative Commons.

\section{Avaliação da Solução}

Para avaliação do jogo educativo ProComunique, antes da reengenharia, ou seja, avaliação Pré-Teste, utilizou-se um grupo composto por 6 (seis) discentes (com experiência acadêmica na avaliação de interfaces) que avaliaram o aplicativo a partir de perguntas derivadas dos princípios de usabilidade da norma ISO/IEC 9126 e 4 opções de respostas na escala Likert. A avaliação, após seguidos os princípios de IHC sugeridas num documento de Projeto de Interface, deu-se através do mesmo questionário e avaliadores estabelecidos para o Pré-Teste.

A partir da análise das médias de pontuação para cada característica, observa-se que os avaliadores consideraram na avaliação pré-teste o ProComunique pouco aderente à norma ISO/IEC 9126. Em contrapartida, na avaliação pós-teste, os avaliadores consideraram o game largamente aderente aos princípios de Usabilidade, conforme apresenta a Figura 4.

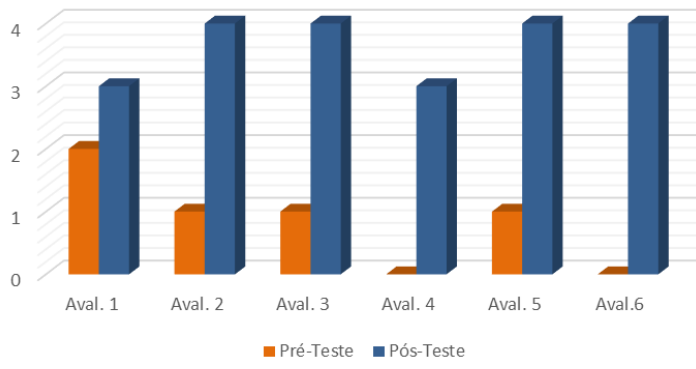

Figura 4: Comparativo de Usabilidade Pré e Pós-Teste

\section{Considerações Finais}

A pesquisa apresentada neste pôster, além de abordar a relação entre as áreas de IHC e jogos educativos, trata de um problema real: o não seguimento de princípios de IHC no desenvolvimento de jogos educativos. Este estudo de caso busca auxiliar desenvolvedores que queiram criar softwares educativos que sejam fáceis de serem utilizados e agradáveis aos usuários, atendendo assim seus objetivos de aprendizagem.

A partir desta pesquisa, conclui-se que é necessário o seguimento desses princípios desde a etapa inicial do processo de desenvolvimento de software, a fim de apoiar o processo de desenvolvimento de jogos educativos e, consequentemente, melhorar a experiência de usuários que fazem uso destes. 